\title{
Control of an Interior Permanent Magnets Screw Motor with Power-saving Axial-gap Displacement Adjustment
}

\author{
Yasutaka Fujimoto, Senier Member, IEEE, Tsubasa Suenaga, and Masato Koyama
}

\begin{abstract}
This paper proposes position and force control of a screw motor with power-saving axial-gap displacement adjustment. The motor has a helical-shape mover, which moves in a helical-shape stator without contact. Due to the fabrication process, the actual helical shapes of the mover and the stator are not completely uniform and the air-gap length between the mover and the stator slightly changes depending on the mover rotation angle. The d-axis current remains a finite value and copper loss arises even when the mover is located at the center between the stator cores. A power-saving axial-gap displacement adjustment method is proposed to solve this problem. The proposed control is experimentally verified.
\end{abstract}

Index Terms-Electric motors, AC motors, permanent magnet motors, servomotors, linear motors, linear actuators, helicalmotion motors, screw motors, spiral motors, gap displacement adjustment, motion control.

\section{INTRODUCTION}

In many advanced nations, due to recent low birthrate and longevity, reduction in labor force and increase in elderly people are becoming a social issue. Manual assist manipulators or lift assist devices with vacuum gripper end-effectors have been widely introduced in production area to handle heavy loads easily. In hospitals and nursing homes, patient lifts are provided for transfers of patients with mobility problems between a bed and a wheelchair. These devices have very limited functions and are too big to use in a small room. Recently, more general assistive devices than ever have been developed. A powered exoskeleton provides mobility assistance for infirm people[1]. Actuators for assistive devices are required to be compact, high-power, safe, and compliant. Especially safety issue is big concern because the devices directly interact with the users. A compliant actuator is defined as an actuator that allows deviations from its own equilibrium position depending on the applied external force[2]. Conventionally, combination of electric rotary motor and high-reduction-ratio gears such as harmonic gears are widely used for robotic application.

Manuscript received October 11, 2012; revised February 18, 2013. Accepted for publication May 29, 2013. This work was supported in part by KAKENHI under Grant 19676003 and 24246047.

Copyright (c) 2013 IEEE. Personal use of this material is permitted. However, permission to use this material for any other purposes must be obtained from the IEEE by sending a request to pubs-permissions@ieee.org

Y. Fujimoto and M. Koyama are with the Department of Electrical and Computer Engineering, Yokohama National University, Yokohama 240-8501 Japan (e-mail: fujimoto@ynu.ac.jp).

T. Suenaga were with the Department of Electrical and Computer Engineering, Yokohama National University, Yokohama 240-8501 Japan. He is now with the Chugai Ro Co., Ltd., Osaka 541-0046, Japan.
The equivalent output inertia drastically increases in inversely proportional to the square of the reduction ratio. This results in a large impulse when the robot collides with a human.

Several approaches have been proposed to overcome this problem. A light-weight robot arm equipped with the $D L R^{1}$ actuators for assistive tasks reduces risk of collision[3]. The actuator is designed so that the total volume becomes minimal and the load torque can be measured by strain gaugebased sensors mounted on the flex spline of the harmonic drive or specially designed beams between the reduction gear and the load. Another approach to reduce impact is series elastic actuators (SEAs)[2][4]-[6]. Springs are installed between a output link and a geared motor. Inertia of the output link and the geared motor are almost decoupled by the springs. Therefore the equivalent output inertia of the actuator does not increase. In addition, these approaches recover the backdrivability of the actuator. However these actuators have a disadvantage of narrow bandwidth of the control systems. Sensing bandwidth of the DLR actuator is limited up to $600 \mathrm{~Hz}$. The control bandwidth of the SEA is less than about one-third of the fundamental resonant frequency, which is typically in the range of $100 \mathrm{~Hz}$ or less. These performances are not enough compared with existing direct-drive actuators.

Pure direct-drive system is almost free from backlash and friction and easy to realize for precise, high-speed, and safe motion. Therefore, from the viewpoint of controllability, the direct-drive systems are suitable for robotics applications. However, conventional direct-drive motors have low load to weight ratio and are too heavy to be installed in assistive devices. Recently, many works on permanent magnet (PM) linear motors have been reported[7]-[19]: tubular linear motors[7][10], switched flux linear motors[11], etc. Some of them deal with design issue of PM linear motors[12]-[15]. Other works on high-temperature superconducting linear motors have been reported[20]. An application of linear motors for haptic devices has been reported[21] where direct-drive feature has an important role in their control systems. Linear actuators using magnetic screw-nut have been proposed[22]-[24], in which helically disposed, radially magnetised permanent magnets are placed on both the screw and the nut. Various types of a 2-DOF motor capable of producing rotary and linear motion have been presented in articles[25]-[36]. There are stepper motors[25][26], induction motors[27][28], reluc-

\footnotetext{
${ }^{1}$ Deutsches Zentrum für Luft- und Raumfahrt (the German Aerospace Center)
} 

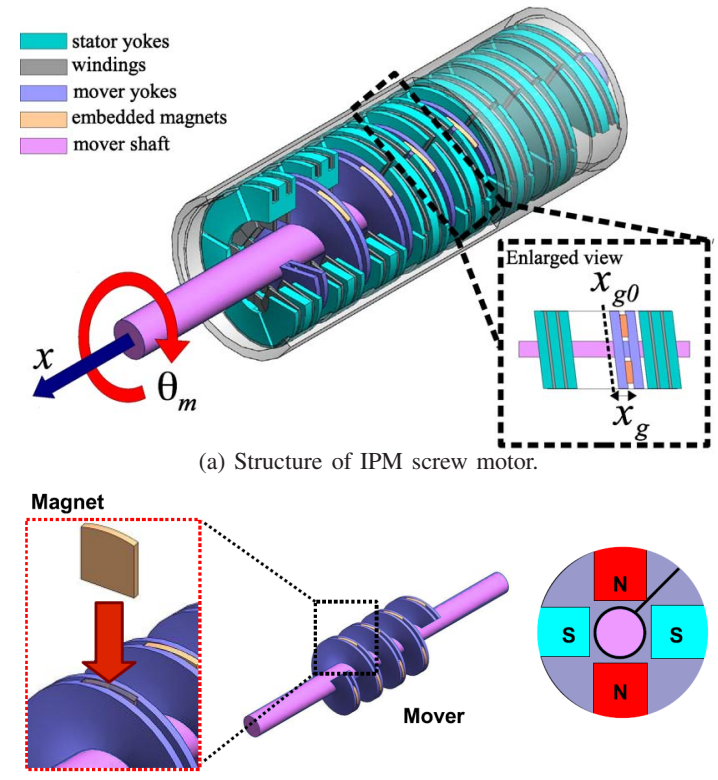

(b) Structure of mover

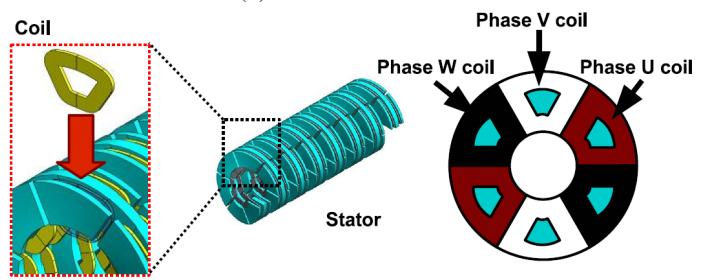

(c) Structure of stator.

Fig. 1. Structure of IPM screw motor.

tance motors[29][30], permanent-magnet motors[31]-[34], and piezoelectric actuators[35][36]. All these 2-DOF motors are radial-gap motors.

There are several approaches to improve the thrust force of linear motors. Thrust force is directly proportional to gap area and inversely proportional to gap length. A method to expand gap area without increasing volume is to design a motor of a special 3-D structure. Authors have proposed a new helical structure of a direct-drive system that meets the requirements of safety, performance, and compactness[37]-[41]. The motor has a helical-shape mover, which moves in a helical-shape stator without contact. Compared with existing rotary-motordriven ballscrew systems, the proposed motor has advantages in terms of safety, compliance, and controllability. However, due to the fabrication process, the actual helical shape of the motor is not completely uniform and the air-gap length between the mover and the stator slightly changes depending on the mover rotation angle. Therefore, the equilibrium point of magnetic attractive force between mover magnets and stator core is not determined easily. The current remains a finite value and copper loss arises when the mover tries to keep axial-gap displacement constant which correspons to nonequilibrium point. In this paper, a power-saving axial-gap displacement control is proposed to solve this problem. The zero-power controls for existing levitating machines have been reported[42]-[44]. In this paper, similar to the zero-power control, a new power-saving axial-gap displacement control for the screw motor is proposed. The proposed control is verified by a couple of experiments.

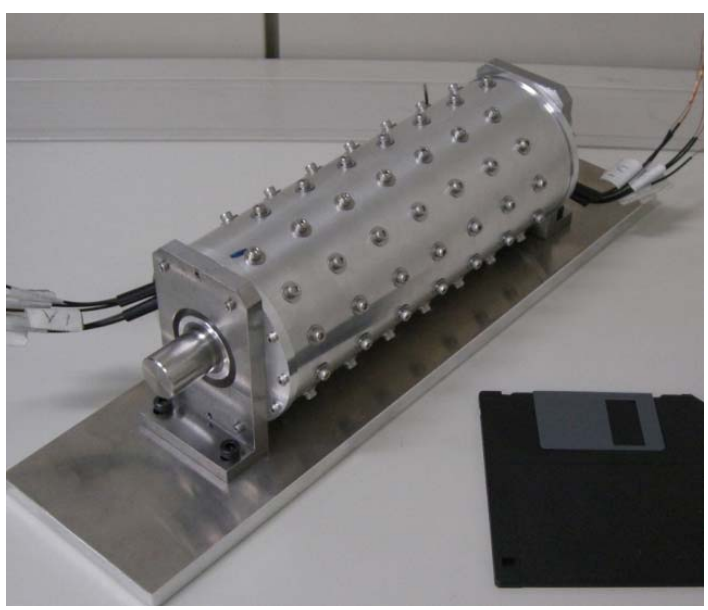

(a) Exterior of IPM screw motor.

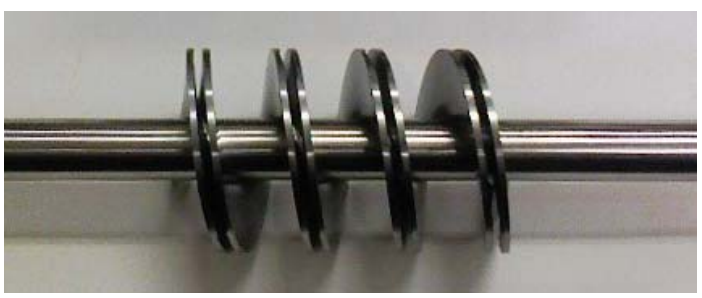

(b) Mover of IPM screw motor.

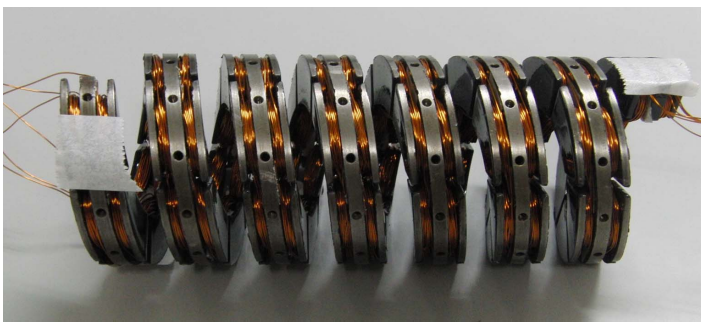

(c) Stator of IPM screw motor.

Fig. 2. Prototype of IPM screw motor.

\section{SCREW MOTOR}

\section{A. Design}

Fig. 1 shows a model of an interior permanent magnet (IPM) type screw motor. The blue part is a helical mover in which permanent magnets colored in the orange are inserted in the mover core made of high-permeability soft-magnetic free-cutting steel MES3F, made by Tohoku Steel, co. ltd, that contains $2.7 \%$ silicon and $0.2 \%$ lead, making it very easy to machine. The shaft colored in the purple is made of nonmagnetic material. Dominant flux of the magnets goes along with the axial direction. The cyan part is a helical stator in which slots are provided for two three-phase windings. Fig. 1 (c) is a schematic view showing the the allocation of the stator windings. The stator is made of bulk steel same as the mover and fabricated by machine tools. Therefore eddy current losses in the stator are higher than those of laminated iron core or soft magnetic composite core. Each of windings interacts with the magnet in the mover iron. The motor is a sort of axialgap permanent magnet synchronous machine. Linear-rotary bearings are installed between the mover and the stator to share the rotating axis and to support the mover against radial 
load force. Therefore the motor has two-degree of motion freedom. One is rotary motion around the axis, and the other is linear motion along with the axis. Each motion is almost independent but subject to limited space of the narrow air gaps. Fig. 2 (a), (b), and (c) show the exterior, the mover, and the stator of a prototype of the screw motor, respectively. As an end-effector of the motor, a rotation cancellation mechanism consisting of angular bearings is attached at the end of the mover shaft to cancel rotary motion and extract linear motion only. In addition, the motor is equipped with a rotary encoder and a linear encoder to measure the rotation angle and linear position of the mover, respectively.

\section{B. Model}

1) Voltage Equation: Voltage equation of the screw motor can be derived from magnetic circuit of the motor[39]. For simplicity, we assume that the iron core is made of linear magnetic material and the permeability of the permanent magnet is equivalent to the permeability of free space. It is also assumed that the edge effect is negligible and the permanent magnets produce a sinusoidally varying magnetic field on concentrated windings. These assumptions give a rough approximation of the actual model, which is sufficient for employing in control system if we conduct parameter identification.

The dq-axis voltage equations for each three-phase windings are represented by

$$
\begin{aligned}
{\left[\begin{array}{c}
V_{1 d} \\
V_{1 q}
\end{array}\right] } & =\left[\begin{array}{cc}
R+L_{1 d}\left(\frac{d}{d t}\right) & 0 \\
0 & R+L_{1 q}\left(\frac{d}{d t}\right)
\end{array}\right]\left[\begin{array}{c}
I_{1 d} \\
I_{1 q}
\end{array}\right] \\
& +\left[\begin{array}{cc}
\dot{x}_{g} L_{1 d} / l_{1} & -p \dot{\theta} L_{1 q} \\
p \dot{\theta} L_{1 d} & \dot{x}_{g} L_{1 q} / l_{1}
\end{array}\right]\left[\begin{array}{c}
I_{1 d} \\
I_{1 q}
\end{array}\right]+\Psi_{1}\left[\begin{array}{c}
\dot{x}_{g} / l_{1} \\
p \dot{\theta}
\end{array}\right] \\
{\left[\begin{array}{c}
V_{2 d} \\
V_{2 q}
\end{array}\right] } & =\left[\begin{array}{cc}
R+L_{2 d}\left(\frac{d}{d t}\right) & 0 \\
0 & R+L_{2 q}\left(\frac{d}{d t}\right)
\end{array}\right]\left[\begin{array}{c}
I_{2 d} \\
I_{2 q}
\end{array}\right] \\
& +\left[\begin{array}{cc}
-\dot{x}_{g} L_{2 d} / l_{2} & -p \dot{\theta} L_{2 q} \\
p \dot{\theta} L_{2 d} & -\dot{x}_{g} L_{2 q} / l_{2}
\end{array}\right]\left[\begin{array}{c}
I_{2 d} \\
I_{2 q}
\end{array}\right]+\Psi_{2}\left[\begin{array}{c}
-\dot{x}_{g} / l_{2} \\
p \dot{\theta}
\end{array}\right]
\end{aligned}
$$

where $V_{i d}$ and $V_{i q}$ are the d-axis and q-axis voltage, $I_{i d}$ and $I_{i q}$ are the d-axis and q-axis current of the windings, respectively. Subscript $i=\{1,2\}$ represents the section of the magnetic circuit; " 1 " corresponds to the back-side windings and " 2 " corresponds to the front-side windings. $L_{i d}$ and $L_{i q}$ are the $\mathrm{d}$-axis and q-axis inductance, respectively. $R$ is the winding resistance on d-axis and q-axis. $\Psi_{i}$ is the field by the permanent magnets. $p$ is the number of pole pairs per 360 degree mechanical angular displacement. $x_{g}$ is the displacement of air gap; $x_{g}=0$ when the mover is at the center between the stator cores. $x$ is the linear position of the mover. $\theta$ is the mechanical rotational angle of the mover. $l_{1}=l-x_{g}$ is the air gap between the back-side stator core and the frontside mover core, and $l_{2}=l+x_{g}$ is the air gap between the front-side stator core and the back-side mover core, where $l$ is nominal air gap. This voltage equations are almost similar to those of conventional rotational synchronous motors except the terms of $\dot{x}_{g}$, velocity of the gap displacement.
2) Motion Equation: Motion equation of the screw motor is obtained from the same magnetic circuit.

$$
\begin{aligned}
M \ddot{x} & =q p\left(f_{1}+f_{2}\right)-f_{d i s} \\
J \ddot{\theta} & =q p\left(\tau_{1}+\tau_{2}\right)
\end{aligned}
$$

where $f_{1}$ and $\tau_{1}$ are thrust-force and torque acting between the back-side stator core and the front-side mover core, respectively, and $f_{2}$ and $\tau_{2}$ are those acting between the front-side stator core and the back-side mover core, respectively. They are given by

$$
\begin{aligned}
f_{1} & =\frac{1}{l_{1}} \Psi_{1} I_{1 d}+\frac{1}{2 l_{1}}\left(L_{1 d} I_{1 d}^{2}+L_{1 q} I_{1 q}^{2}+L_{1 f} I_{1 f}^{2}\right) \\
\tau_{1} & =p\left(\Psi_{1} I_{1 q}+\left(L_{1 d}-L_{1 q}\right) I_{1 d} I_{1 q}\right)-h f_{1} \\
f_{2} & =-\frac{1}{l_{2}} \Psi_{2} I_{2 d}-\frac{1}{2 l_{2}}\left(L_{2 d} I_{2 d}^{2}+L_{2 q} I_{2 q}^{2}+L_{2 f} I_{2 f}^{2}\right) \\
\tau_{2} & =p\left(\Psi_{2} I_{2 q}+\left(L_{2 d}-L_{2 q}\right) I_{2 d} I_{2 q}\right)+h f_{2}
\end{aligned}
$$

where $M, J$ are mass and inertia of the mover, respectively. $f_{d i s}$ is disturbance force applied to the mover. $h=l_{p} / 2 \pi$ is an axial screw length per rotation angle in radian where $l_{p}$ is lead of the screw which is an axial travel of the screw during a single revolution. $q$ is the number of layers of the screw. $I_{i f}$ is the equivalent field current by the permanent magnets and $L_{\text {if }}$ is the corresponding self-inductance. Previously defined $\Psi_{i}$, the field by the permanent magnets, correspons to a product of $I_{i f}$ and the mutual inductance between $I_{i f}$ and $I_{i d}$.

The gap displacement $x_{g}$, the linear position $x$, and the rotation angle $\theta$ have a relation such that:

$$
x_{g}=x-h \theta
$$

subject to $\left|x_{g}\right| \leq l_{g}$ where $l_{g}$ is the maximum gap displacement. If the gap displacement $x_{g}$ is controlled to be zero, then the mover is located at the center between the stator cores and $x=h \theta$ holds from (9). This relationship corresponds to the ideal screw in which the rotation angle $\theta$ is in proportion to the linear position $x$.

With a back EMF compensation and the PI current feedback, the currents of the windings can be controlled stably within $1 \mathrm{~ms}$. The back EMF, the second and third terms of the right-hand sides of (1) and (2), can be cancelled by adding these calculated values to the voltage references for $V_{i d}$ and $V_{i q}$. By using the current controller, we can control each current such that $I_{d}^{r e f}=I_{1 d}=-I_{2 d}$ and $I_{q}^{r e f}=I_{1 q}=I_{2 q}$. Then, the motion equation (3)(4) can be approximated and simply rewritten as follows.

$$
\begin{aligned}
M \ddot{x} & =K_{f} I_{d}^{r e f}+K_{g}\left(x_{g}-x_{g 0}\right)-f_{d i s} \\
J \ddot{\theta} & =K_{\tau} I_{q}^{r e f}-h K_{f} I_{d}^{r e f}-h K_{g}\left(x_{g}-x_{g 0}\right)
\end{aligned}
$$

where $K_{f}$ and $K_{\tau}$ are thrust and torque constants, respectively. $K_{g}$ is a negative spring coefficient due to the magnetic attractive force acting between the permanent magnet and the stator iron core. $x_{g 0}$ is introduced to represents equilibrium point of the gap displacement which is ideally zero. 


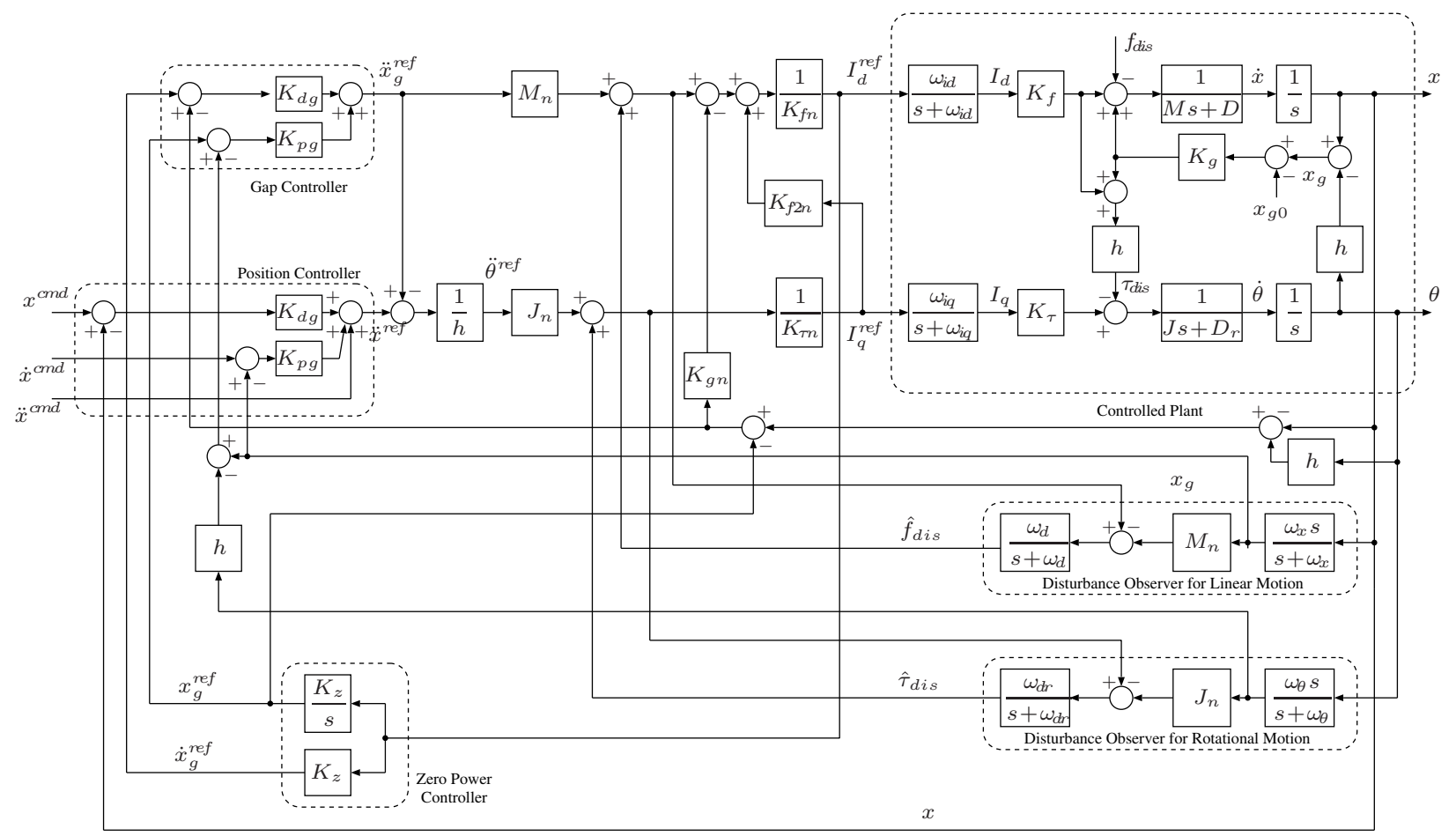

Fig. 3. Block diagram of position control system with power-saving axial-gap displacement adjustment.

3) Gap Dynamics: Dynamics of the gap displacement can be derived from (10) and (11) as follows.

$$
\begin{aligned}
M \ddot{x}_{g} & =(1+r h)\left(K_{f} I_{d}^{r e f}+K_{g}\left(x_{g}-x_{g 0}\right)\right) \\
& -r K_{\tau} I_{q}^{r e f}-f_{d i s}
\end{aligned}
$$

where $r=h M / J$. Assume that the term $r h$ is small enough, i. e., $r h \ll 1$, then we have

$$
M \ddot{x}_{g}=K_{f} I_{d}^{r e f}-K_{f 2} I_{q}^{r e f}+K_{g}\left(x_{g}-x_{g 0}\right)-f_{d i s}
$$

where $K_{f 2}=r K_{\tau}$. Note that dynamics of the gap displacement (13) is similar to that of the linear motion (10), however it is affected by the q-axis current.

Note that $L_{i d}=L_{i q}$ holds because the screw motor in this paper does not have saliency while it is an IPM type motor.

\section{Control}

1) Power-saving Axial-gap Displacement Control: In order to realize direct-drive motion, axial-gap displacement control is applied to the screw motor. When the axial-gap displacement controller stabilizes the axial-gap, the mover does not contact to the stator except franges that support the mover shaft. Therefore the mover is almost free from backlash and friction. Based on the model (13), the d-axis current is determined to stabilize the gap displacement as follows.

$$
\begin{aligned}
& I_{d}^{r e f}=\frac{1}{K_{f n}}\left(M_{n} \ddot{x}_{g}^{r e f}-K_{g n} x_{g}+K_{f 2 n} I_{q}^{r e f}+\hat{f}_{d i s}\right) \\
& \ddot{x}_{g}^{r e f}=K_{g p}\left(x_{g}^{r e f}-x_{g}\right)+K_{g d}\left(\dot{x}_{g}^{r e f}-\dot{x}_{g}\right) .
\end{aligned}
$$

The subscript $n$ represents nominal parameters. The gain $K_{p}$ and $K_{d}$ are chosen such that $M_{n} s^{2}+K_{d} s+K_{p}$ is stable. $\hat{f}_{d i s}$ is estimated disturbance by the disturbance observer:

$$
\hat{f}_{d i s}=\frac{\omega_{d}}{s+\omega_{d}}\left(K_{f n} I_{d}^{r e f}+K_{g n} x_{g}-K_{f 2} I_{q}^{r e f}-M_{n} s \dot{x}_{g}\right) .
$$

As the result, the dynamics of the gap displacement follows the model:

$$
\begin{aligned}
\ddot{x}_{g} & =K_{g p}\left(x_{g}^{r e f}-x_{g}\right)+K_{g d}\left(\dot{x}_{g}^{r e f}-\dot{x}_{g}\right) \\
& -K_{g} x_{g 0}-\left(f_{d i s}-\hat{f}_{d i s}\right) .
\end{aligned}
$$

Copper loss arises when the axial-gap displacement controller tries to keep the axial-gap displacement at nonequilibrium point. In order to solve this problem, powersaving axial-gap displacement control is proposed here. To find the equilibrium gap displacement $x_{g 0}$, the reference of the gap displacement is given by

$$
\begin{aligned}
& x_{g}^{r e f}=K_{z} \int I_{d}^{r e f} d t \\
& \dot{x}_{g}^{r e f}=K_{z} I_{d}^{r e f}
\end{aligned}
$$

where $K_{z}$ is the gain of the controller. The gap reference $x_{g}^{r e f}$ is expected to converge to the equilibrium point and the d-axis current $I_{d}^{r e f}$ converge to zero. From (10), the d-axis current $I_{d}^{r e f}$ and the gap displacement $x_{g}$ have opposite sign in the steady state. Therefore, if $x_{g}>x_{g 0}$ then $I_{d}^{r e f}<0$ and the gap reference $x_{g}^{r e f}$ in (18) decreases until $x_{g}^{r e f}$ reaches $x_{g 0}$.

2) Position Control: Various type of control, such as position control, force control, etc., can be realized by using the q-axis current $I_{q}$ after applying the above mentioned axialgap displacement control. In this section, position control is proposed. 


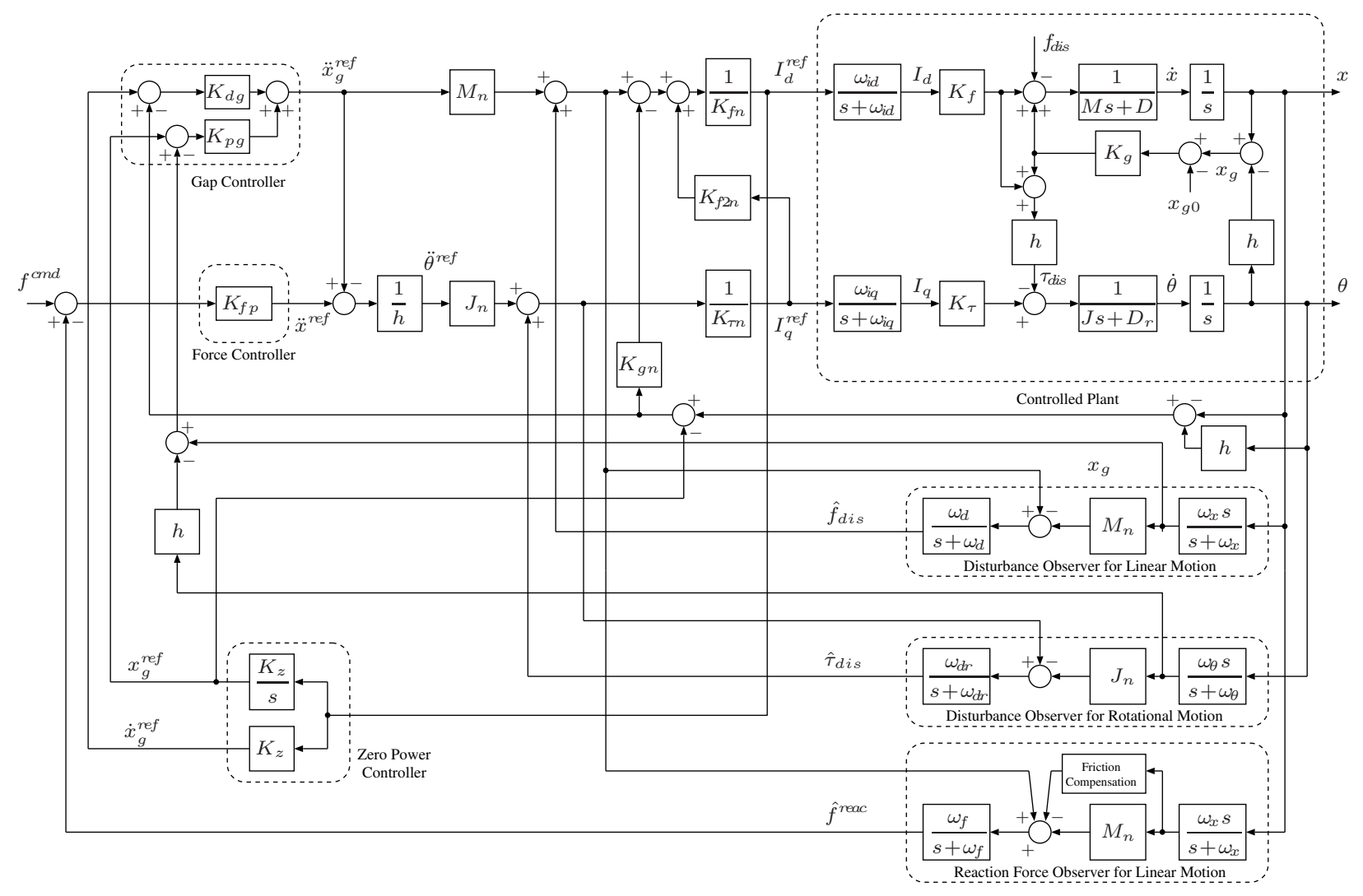

Fig. 4. Block diagram of force control system with power-saving axial-gap displacement adjustment.

The acceleration control is realized first by using disturbance observer. From (9), the acceleration reference of the rotation angle of the mover is obtained from the linear acceleration of the mover and the acceleration of the gap displacement.

$$
\ddot{\theta}^{r e f}=\frac{1}{h}\left(\ddot{x}^{r e f}-\ddot{x}_{g}^{r e f}\right) .
$$

In order to realize above angular acceleration reference $\ddot{\theta}^{\text {ref }}$, the following acceleration controller is considered. The rotational motion equation (11) can be rewritten as

$$
\begin{aligned}
J \ddot{\theta} & =K_{\tau} I_{q}^{r e f}-\tau_{\text {dis }} \\
\tau_{\text {dis }} & =h K_{f} I_{d}^{r e f}+h K_{g}\left(x_{g}-x_{g 0}\right)
\end{aligned}
$$

where $\tau_{d i s}$ is defined as a torque disturbance. From (21) we have an acceleration controller

$$
\begin{aligned}
I_{q}^{r e f} & =\frac{1}{K_{\tau n}}\left(J_{n} \ddot{\theta}^{\text {ref }}+\hat{\tau}_{d i s}\right) \\
\hat{\tau}_{d i s} & =\frac{\omega_{d r}}{s+\omega_{d r}}\left(K_{\tau n} I_{q}^{r e f}-J_{n} s \dot{\theta}\right) .
\end{aligned}
$$

where $\hat{\tau}_{d i s}$ is an estimated torque disturbance obtained by the disturbance observer(24)[45] and $\omega_{d r}$ is the observer gain. The subscript ' $n$ ' represents a nominal value of the parameter. The symbol $s$ represents the complex argument for the Laplace transform.

After applying the acceleration controller, the position controller is designed. It is realized by a PD feedback as follows,

$$
\ddot{x}^{r e f}=K_{p p}\left(x^{c m d}-x\right)+K_{p p}\left(\dot{x}^{c m d}-\dot{x}\right)+\ddot{x}^{c m d}
$$

where the superscript ' $\mathrm{cmd}$ ' represents a command value of the variable. Usually the command values are given by a highlevel controller. The block diagram of the whole position control system is shown in Fig. 3.

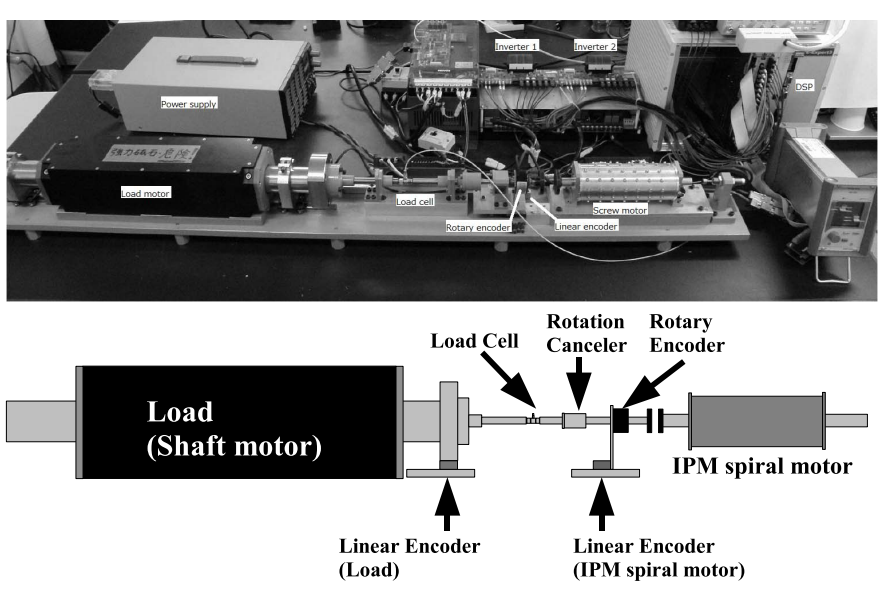

Fig. 5. Experimental apparatus.

3) Force Control: In this section, force control using the q-axis current $I_{q}$ after applying the axial-gap displacement control in the section II-C1. is proposed.

After applying the acceleration controller (20)-(24) as same as the position controller, the force controller is designed. It is realized by a simple proportional control with reaction force 


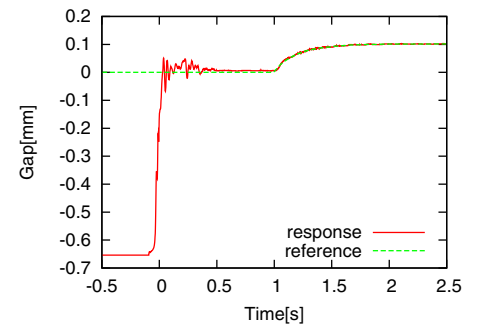

(a) Response of the gap displacement.

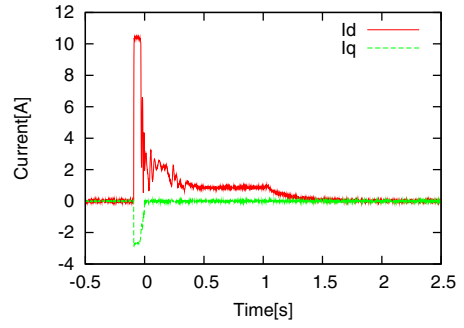

(b) Response of the currents.

Fig. 6. Power-saving axial-gap displacement control.

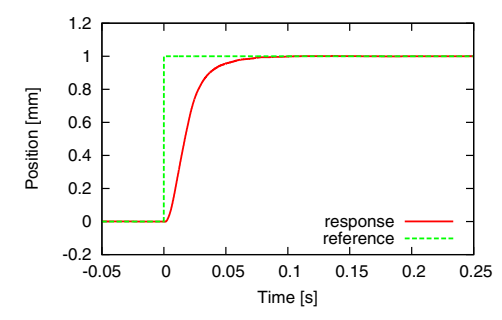

(a) Response of the mover position.

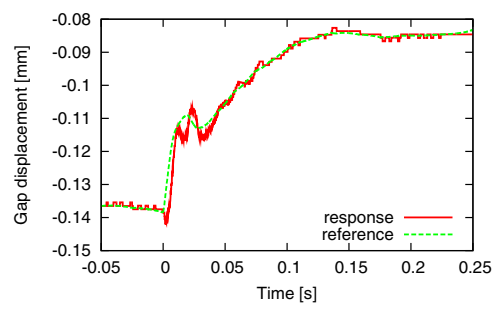

(b) Response of the gap displacement.

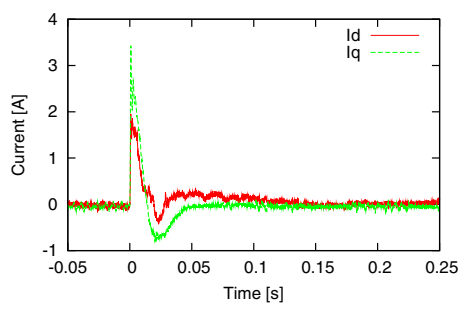

(c) Response of the currents.

Fig. 7. Position control with power-saving axial-gap displacement control. (step reference)

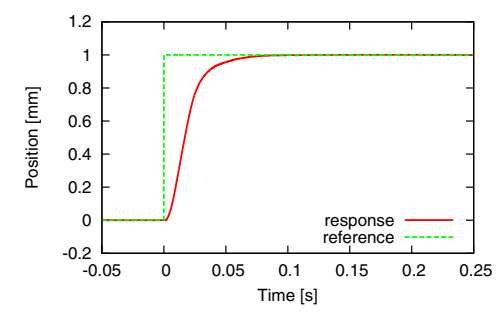

(a) Response of the mover position.

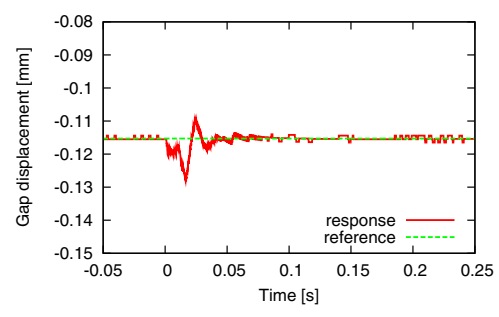

(b) Response of the gap displacement.

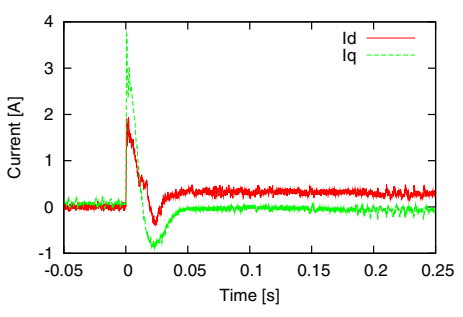

(c) Response of the currents.

Fig. 8. Position control without power-saving axial-gap displacement control. (step reference)

estimator[46] as follows,

$$
\begin{aligned}
\ddot{x}^{r e f} & =K_{f p}\left(f^{c m d}-\hat{f}^{r e a c}\right) \\
\hat{f}^{r e a c} & =\frac{\omega_{f}}{s+\omega_{f}}\left(K_{f n} I_{d}^{r e f}+K_{g n}\left(x_{g}-x_{g 0}\right)\right. \\
& \left.-K_{f 2 n} I_{q}^{r e f}-M_{n} s \dot{x}_{g}\right) .
\end{aligned}
$$

The block diagram of the whole force control system is shown in Fig. 4.

\section{EXPERIMENTS}

Experiments were conducted to verify the proposed axialgap displacement control, position control, and force control described in the section II-C. The parameters are shown in Table I. Apparatus for experiments are shown in Fig. 5 and Table II. A rotary encoder attached to the mover shaft generates 5000 pulses/r. The resolution of the rotary encoder is $\pi / 10000 \mathrm{rad}$ using quad edge evaluation method. A linear encoder is attached to the motor with a resolution of $1 \mu \mathrm{m}$ using quad edge evaluation method. Two independent threephase inverters, working at a $15-\mathrm{kHz}$ switching frequency, are used for driving the screw motor. Three-phase currents are measured using two current sensors and captured into a DSP via A/D converter board at every sampling period of $66.7 \mu \mathrm{s}$.
TABLE I

PARAMETERS 


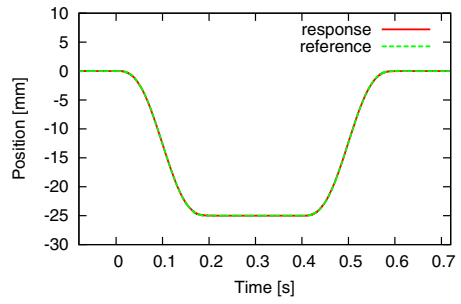

(a) Response of the mover position.

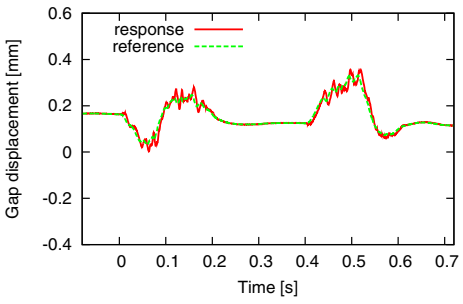

(b) Response of the gap displacement.

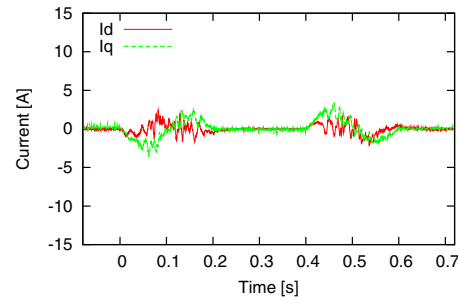

(c) Response of the currents.

Fig. 9. Position control. (long stroke reference, without load)

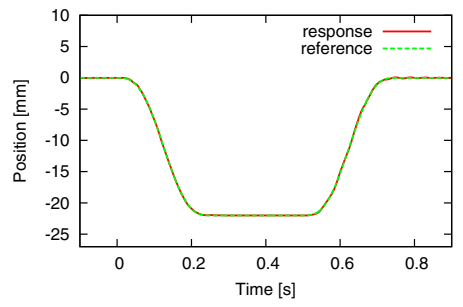

(a) Response of the mover position.

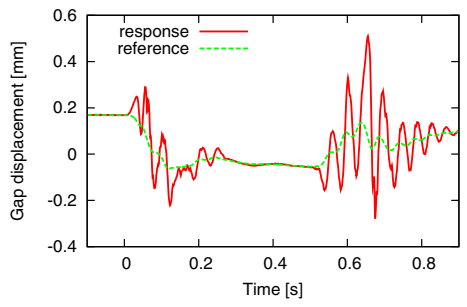

(b) Response of the gap displacement.

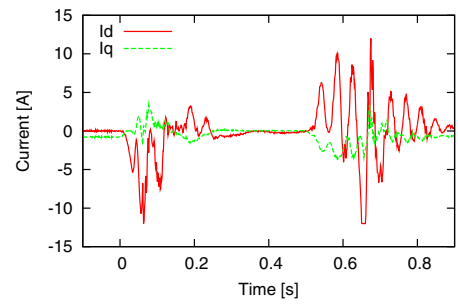

(c) Response of the currents.

Fig. 10. Position control. (long stroke reference, with load)

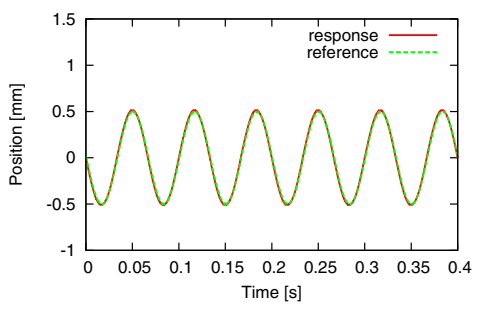

(a) Response of the mover position.

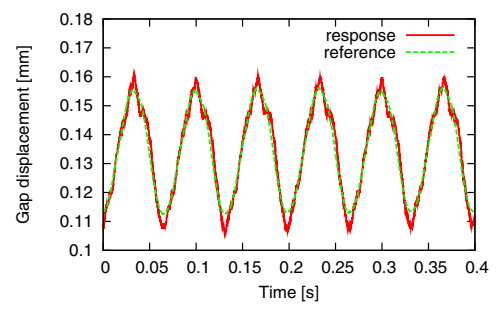

(b) Response of the gap displacement.

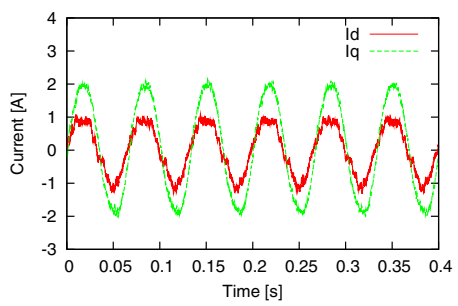

(c) Response of the currents.

Fig. 11. Position control. (sinusoidal reference)

TABLE II

EXPERIMENTAL SETUP

\begin{tabular}{c|c|c}
\hline Unit name & Model designation & Manufacturer \\
\hline \hline Linear encoder & LIE5 1PL3FD & SUMTAK \\
\hline Rotary encoder & MEH30-5000PE & Microtech Laboratory \\
\hline Controller & MW-PE3 & Myway Plus \\
\hline Load cell & 9301B & KISTLER \\
\hline Load motor & S500Q & GMC Hillstone \\
\hline \hline
\end{tabular}

\section{A. Power-saving Axial-gap Displacement Control}

Fig. 6 shows experimental results of the power-saving axial-gap displacement control. Initially, the mover is in a touch-down state due to the magnetic force. Once the gap displacement control (14)-(16) is activated, the mover stably levitated at the center of the air gap where the gap reference $x_{g}^{r e f}$ is set to zero. The power-saving axial-gap displacement control (18)(19) is activated at $t=1 \mathrm{~s}$, then the gap reference changes so that the d-axis current goes to zero.

\section{B. Position Control}

Fig. 7-11 show experimental results of the position control.

The step references are given in Fig. 7 and 8. In these experiments, the mover is initially in a levitating state by the axial-gap displacement control with the power-saving axial- gap displacement control in Fig. 7 and without the powersaving axial-gap displacement control in Fig. 8. Almost same position responses are obtained as shown in Fig. 7 (a) and Fig. 8 (a). The gap responses under the power-saving axialgap displacement control vary according to the change of the equilibrium point as shown in Fig. 7 (b). The proposed powersaving axial-gap displacement control successfully achieves zero d-axis current convergence as shown in Fig. 7 (c) while the d-axis current under the non-power-saving axial-gap displacement control remains a certain value as shown in Fig. 8 (c).

Fig. 9 shows a long stroke response under the position control with the power-saving axial-gap displacement adjustment. The linear position of the mover accurately follows the reference as shown in Fig. 9 (a). In Fig. 9 (b), the gap displacement follows the reference generated by power-saving axial-gap displacement controller. During the acceleration and deceleration periods, the gap displacement goes to the equilibrium point between the permanent magnet force and inertial force. Thus, the wave form in Fig. 9 (b) is similar to the acceleration pattern. In Fig. 9 (c), zero d-axis current is achieved in the steady state and there are transient states during the accelerating and decelerating motion due to the delay of the power-saving axial-gap displacement control. Meanwhile, the $\mathrm{q}$-axis current drives the mover. The accelerating and 


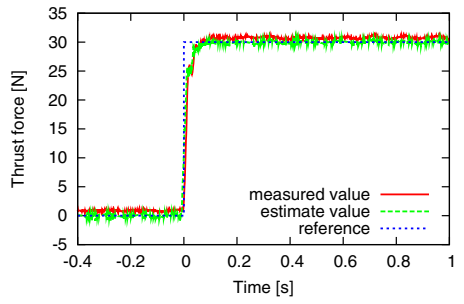

(a) Response of the thrust-force. (reference value: $30 \mathrm{~N}$ )

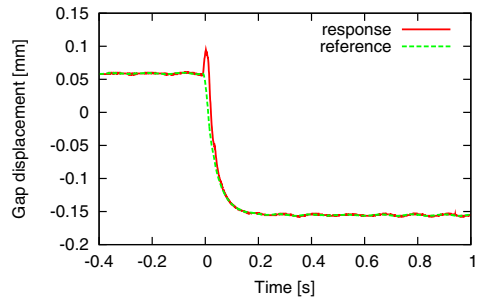

(b) Response of the gap displacement.

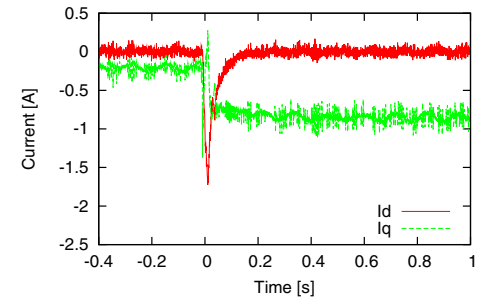

(c) Response of the currents.

Fig. 12. Force control with power-saving axial-gap displacement control.

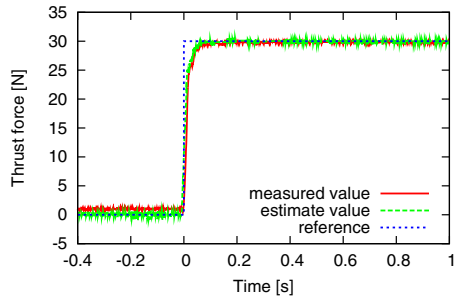

(a) Response of the thrust-force. (reference value: $30 \mathrm{~N}$ )

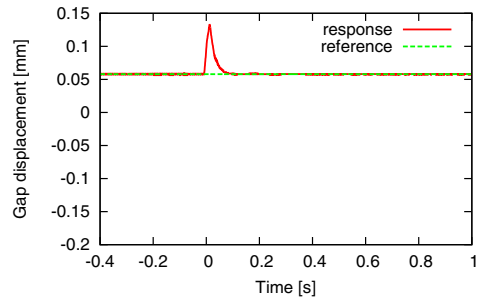

(b) Response of the gap displacement.

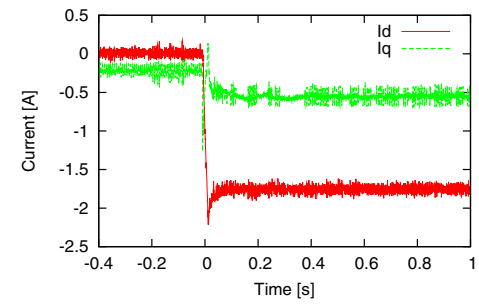

(c) Response of the currents.

Fig. 13. Force control without power-saving axial-gap displacement control.

decelerating force of the mover are generated by the q-axis current.

Fig. 10 shows similar experimental results of a long stroke response under the position control under load force of $30 \mathrm{~N}$ generated by the load motor. The load motor is controlled to generate constant thrust force. Fig. 10 (a) shows position response, Fig. 10 (b) shows gap displacement, and Fig. 10 (c) shows d-axis and q-axis currents. Fluctuations of gap displacement and currents are relatively bigger than the case in Fig. 9 especially in the transient state, that is still open problem.

Fig. 11 shows a sinusoidal response under the position control with the power-saving axial-gap displacement adjustment. The frequency of the sinusoidal reference is set to $15 \mathrm{~Hz}$. The linear position of the mover and the gap displacement accurately follow the references as shown in Fig. 11 (a) and (b), respectively. The gap displacement is almost similar to the acceleration of the mover in order to balance the permanent magnet force and inertial force. In Fig. 11 (c), the d-axis current is used to change the gap displacement and the q-axis current is used to drive the motor.

\section{Force Control}

Fig. 12 and 13 show experimental results of the force control with and without the power-saving axial-gap displacement adjustment, respectively. A fixed tubular linear motor is provided as the load of the force control. In both cases, the measured force and estimated force follow the command value, which is $30 \mathrm{~N}$, as shown in Fig. 12 (a) and Fig. 13 (a).

Under the power-saving axial-gap displacement control, the gap displacement converges to the equilibrium point -0.15 $\mathrm{mm}$ as shown in Fig. 12 (b), where the permanent magnet force $K_{g}\left(x_{g}-x_{g 0}\right)$ in (10) is balanced with the reaction force of $30 \mathrm{~N}$. The d-axis current converges to zero thanks to the power-saving axial-gap displacement control as shown in Fig.
12 (c). The q-axis current remains a certain value in order to push the load.

On the other hand, without the power-saving axial-gap displacement control, the reference of the gap displacement is always constant as shown in Fig. 13 (b). Continuous d-axis current is required to generate the thrust force $K_{f} I_{d}$ in (10) that balances with the reaction force of $30 \mathrm{~N}$ as shown in Fig. 13 (c).

\section{CONCLUSION}

In this paper, posotion control and force control with powersaving axial-gap displacement adjustment for the screw motor have been proposed. The equilibrium point of the magnetic attractive force between the mover magnet and the stator iron varies depending on the mover rotation angle. The experimental results show that, by the proposed controls, the axial-gap displacement is adjusted so that the d-axis current becomes almost zero even when the load force exists. The direct-drive motion has been realized by the proposed controller.

\section{REFERENCES}

[1] H. Kawamoto and Y. Sankai, "Power assist method based on phase sequence and muscle force condition for HAL," Advanced Robotics, vol. 19 , no. 7, pp. 717-734, 2005 .

[2] R. Ham, T. Sugar, B. Vanderborght, K. Hollander, and D. Lefeber, "Compliant actuator designs," IEEE Robot. Autom. Mag., vol. 16, no. 3 , 81-94, 2009.

[3] A. Albu-Schäffer, et al., "The DLR lightweight robot — design and control concepts for robots in human environments," Industrial Robot, vol. 34 , no. 5, 2007.

[4] C. A. Ihrke, et al., "Rotary series elastic actuator," U.S. Patent, Pub. No. US2011/0067517A1, 2012.

[5] R. Filippini, S. Sen, and A. Bicchi, "Toward soft robots you can depend on," IEEE Robot. Autom. Mag., vol. 15, no. 3, pp. 31-41. 2008.

[6] M. Laffranchi, N. Tsagarakis, and D. G. Caldwell, "A compact compliant actuator with variable physical damping," in Proc. IEEE ICRA, 2011, pp. 4644-4650.

[7] J. Wang and D. Howe, "Tubular modular permanent-magnet machines equipped with quasi-Halbach magnetized magnets - Part II: Armature reaction and design optimization," IEEE Trans. Magn., vol. 41, no. 9, pp. 2479-2489, Sep. 2005. 
[8] F. Cupertino, P. Giangrande, G. Pellegrino, and L. Salvatore, "End effects in linear tubular motors and compensated position sensorless control based on pulsating voltage injection," IEEE Trans. Ind. Electron., vol. 58, no. 2, pp. 494-502, 2011.

[9] F. Marignetti, S. Carbone, V. Delli Colli, and C. Attaianese, "Cryogenic characterization of copper-wound linear tubular actuators," IEEE Trans. Ind. Electron., vol. 59, no. 5, pp. 2167-2177, 2012.

[10] J. Zou, et al., "Development and analysis of tubular transverse flux machine with permanent-magnet excitation," IEEE Trans. Ind. Electron., vol. 59, no. 5, pp. 2198-2207, 2012.

[11] C. F. Wang and J. X. Shen, "A method to segregate detent force components in permanent-magnet flux-switching linear machines," IEEE Trans. Magn., vol. 48, no. 5, pp. 1948-1955, 2012.

[12] X. Chen and Z. Q. Zhu, "Analytical determination of optimal split ratio of E-core permanent magnet linear oscillating actuators," IEEE Trans. Ind. Appl., vol. 47, no. 1, pp. 25-33, 2011.

[13] H. M. Hasanien, "Particle swarm design optimization of transverse flux linear motor for weight reduction and improvement of thrust force," IEEE Trans. Ind. Electron., vol. 58, no. 9, pp. 4048-4056, 2011.

[14] N. Hodgins, O. Keysan, A. S. McDonald, and M. A. Mueller, "Design and testing of a linear generator for wave-energy applications," IEEE Trans. Ind. Electron., vol. 59, no. 5, pp. 2094-2103, 2012.

[15] R. Vermaak and M. J. Kamper, "Design aspects of a novel topology aircored permanent magnet linear generator for direct drive wave energy converters," IEEE Trans. Ind. Electron., vol. 59, no. 5, pp. 2104-2115, 2012.

[16] K. Sato, M. Katori, and A. Shimokohbe, "Ultrahigh-acceleration moving-permanent-magnet linear synchronous motor with a long working range," IEEE/ASME Trans. Mech., vol. 18, no. 1, pp. 307-315, 2013.

[17] M. Carpita, T. Beltrami, C. Besson, and S. Gavin, "Multiphase active way linear motor: proof-of-concept prototype," IEEE Trans. Ind. Electron., vol. 59, no. 5, pp. 2178-2188, 2012.

[18] E. Kazan and A. Onat, "Modeling of air core permanent-magnet linear motors with a simplified nonlinear magnetic analysis," IEEE Trans. Magn., vol. 47, no. 6, pp. 1753-1762, 2011.

[19] C. Pompermaier, et al., "Small linear PM oscillatory motor: magnetic circuit modeling corrected by axisymmetric 2-D FEM and experimental characterization," IEEE Trans. Ind. Electron., vol. 59, no. 3, pp. 1389 1396,2012

[20] J. X. Jin, L. H. Zheng, Y. G. Guo, and J. G. Zhu, "Performance characteristics of an HTS linear synchronous motor with HTS bulk magnet secondary," IEEE Trans. Ind. Appl., vol. 47, no. 6, pp. 24692477,2011

[21] H. Kuwahara, et al., "Abstraction of action components unconstrained by alignment of haptic sensing points," IEEE Trans. Ind. Electron., vol. 58, no. 8, pp. 3196-3204, 2011.

[22] J. Hashimoto and Y. Kubo, "Magnetic screw device," U.S. Patent, No. $5687614,1997$.

[23] N. G. Vitale, "Rotary torque to axial force energy conversion apparatus," U.S. Patent, No. 5984960, 1999.

[24] J. Wang, K. Atallah, and W. Wang, "Analysis of a magnetic screw for high force density linear electromagnetic actuators," IEEE Trans. Magn., vol. 47, no. 10, pp. 4477-4480, 2011.

[25] T. Higuchi, "Magnetically suspended stepping motors for clean room and vacuum environments," in Proc. Int. Symp. on Magnetic Suspension Technology, part 2, 1994, pp. 625-639.

[26] R. Hammer, "A combined linear-rotary direct drive step motor," European Patent Application, pub. no. EP0482321, 1992.

[27] J. H. H. Alwash, A. D. Mohssen, and A. S. Abdi, "Helical motion tubular induction motor," IEEE Trans. Energy Convers., vol. 18, no. 3, pp. 362-369, Sep. 2003.

[28] E. Amiri, P. Gottipati, E. A. Mendrela, "3-D space modeling of rotarylinear induction motor with twin-armature," in Proc. Int. Conf. on Electrical Energy Systems, 2011, pp. 203-206.

[29] J. F. Pan, N. C. Cheung, and G-Z. Cao, "Investigation of a rotary-linear switched reluctance motor," in Proc. ICEM, 2010, pp. 1-4.

[30] L. Szabo, I. Bentia, M. Ruba, "A rotary-linear switched reluctance motor for automotive applications," in Proc. ICEM, 2012, pp. 2615-2621.

[31] A. Chitayat, "Rotary-linear actuator," U.S. Patent, No. US6215206B1, 2001.

[32] G. Krebs, et al., "Modeling of a linear and rotary permanent magnet actuator," IEEE Trans. Magn., vol. 44, no. 11, pp. 4357-4360, 2008.

[33] S. Makino, T. Shikayama, and H. Yahara, "Actuator," European Patent Application, pub. no. EP2403118A2, 2012

[34] Ping Jin, et al., "A novel linear and rotary Halbach permanent magnet actuator with two degrees-of-freedom," J. Appl. Phys., vol. 111, 07E725, 2012.
[35] M. Rakotondrabe, "Development, modeling, and control of a micro/nanopositioning 2-DOF stick-slip device," IEEE/ASME Trans. Mech., vol. 14, no. 6, pp. 733-745, Dec. 2009.

[36] T. Mashimo and S. Toyama, "Rotary-linear piezoelectric microactuator with a cubic stator of side length $3.5 \mathrm{~mm}$," IEEE Trans. Ultrason. Ferroelectr. Freq. Control, vol. 57, no. 8, pp. 1825-1830, 2010.

[37] Y. Fujimoto, T. Kominami, and H. Hamada, "Development and analysis of a high thrust force direct-drive linear actuator," IEEE Trans. Ind. Electron., vol. 56, no. 5, pp. 1383-1392, 2009.

[38] I. A. Smadi, H. Omori, and Y. Fujimoto, "Development, analysis and experimental realization of a direct-drive helical motor," IEEE Trans. Ind. Electron., vol. 59, no. 5, pp. 2208-2216, 2012.

[39] Y. Fujimoto, et al., "Modeling and control of a high-thrust direct-drive spiral motor," in Proc. IEEJ IPEC, 24F1-4, 2010, pp. 2222-2229.

[40] Y. Fujimoto, I. A. Smadi, and Y. Wakayama, "Development of musculoskeletal biped robot driven by direct-drive actuators," in Proc. IEEE ICM, ID-007447, 2011.

[41] Y. Fujimoto, et al., "Force control of a spiral motor and its application to musculoskeletal biped robot," in Proc. IEEE AMC, pp. 1-6, 2012.

[42] Md. E. Hoque, M. Takasaki, Y. Ishino, and T. Mizuno, "Development of a three-axis active vibration isolator using zero-power control," IEEE/ASME Trans. Mech., vol. 11, no. 4, pp. 462-470, 2006.

[43] M. E. Hoque, T. Mizuno, Y. Ishino, and M. Takasaki, "A 3-DOF modular vibration isolation system using zero-power magnetic suspension with adjustable negative stiffness," in Proc. IEEE AMC, 2010, pp. 661-666.

[44] K. Erkan, B. Okur, T. Koseki, and F. Yigit, "Experimental evaluation of zero-power levitation control by transfer function approach for a 4-pole hybrid electromagnet," in Proc. IEEE ICM, 2011, pp. 23-28.

[45] K. Ohnishi, M. Shibata, and T. Murakami, "Motion control for advanced mechatronics," IEEE/ASME Trans. Mech., vol. 1, no. 1, pp. 56-67, March 1996.

[46] T. Murakami, F. Yu, and K. Ohnishi, "Torque sensorless control in multidegree-of-freedom manipulator," IEEE Trans. Ind. Electron., vol. 40, no. 2, pp. 259-265, 1993.

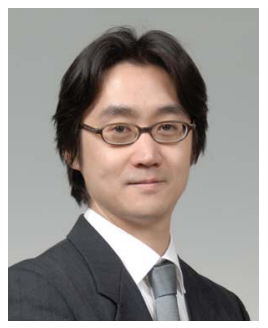

Yasutaka Fujimoto (S'93-M'98-SM'12) received the B.E., M.E., and Ph.D. degrees in electrical and computer engineering from Yokohama National University, Yokohama, Japan, in 1993, 1995, and 1998, respectively. In 1998, he joined Keio University, Yokohama, Japan. Since 1999, he has been with Yokohama National University, where he is currently, a Professor. His research interests include actuators, robotics, and motion control.

Dr. Fujimoto is a member of IEE of Japan and Robotics Society of Japan.

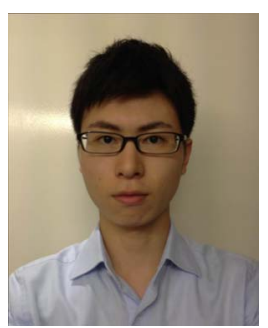

Tsubasa Suenaga received the B.E. and M.E. degrees in electrical and computer engineering from Yokohama National University, Yokohama, Japan, in 2010 and 2012, respectively. Since 2012, he has been with Chugai Ro Co., Ltd., Osaka, Japan. His research interests include thermal technology.

Mr. Suenaga is a member of Robotics Society of Japan.

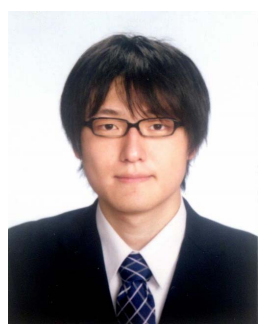

Masato Koyama received the B.E. degree in electrical and computer engineering from Kisarazu National College of Technology, Chiba, Japan, in 2012. Since 2012, he has been with Yokohama National University, Yokohama, Japan, where he is currently working toward the M.E. degree in the Department of Electrical and Computer Engineering. His research interests include control of linear actuators.

Mr. Koyama is a member of IEE of Japan. 